Article

\title{
Entropy and Exergy Analysis of a Heat Recovery Vapor Generator for Ammonia-Water Mixtures
}

\author{
Kyoung Hoon Kim ${ }^{1}$, Kyoungjin $\mathrm{Kim}^{2}$ and Hyung Jong Ko ${ }^{1, *}$
}

1 Department of Mechanical Engineering, Kumoh National Institute of Technology, 61 Daehak-ro, Gumi, Gyeongbuk 730-701, Korea; E-Mail: khkim@kumoh.ac.kr

2 Department of Mechanical System Engineering, Kumoh National Institute of Technology, 61 Daehak-ro, Gumi, Gyeongbuk 730-701, Korea; E-Mail: kimkj@kumoh.ac.kr

* Author to whom correspondence should be addressed; E-Mail: kohj@kumoh.ac.kr; Tel.: +82-54-478-7295; Fax: +82-54-478-7319.

Received: 6 January 2014; in revised form: 7 April 2014 / Accepted: 9 April 2014 / Published: 11 April 2014

\begin{abstract}
Recently power generation systems using ammonia-water binary mixtures as a working fluid have been attracting much attention for their efficient conversion of low-grade heat sources into useful energy forms. This paper presents the First and Second Law thermodynamic analysis for a heat recovery vapor generator (HRVG) of ammonia-water mixtures when the heat source is low-temperature energy in the form of sensible heat. In the analysis, key parameters such as ammonia mass concentration and pressure of the binary mixture are studied to investigate their effects on the system performance, including the effectiveness of heat transfer, entropy generation, and exergy efficiency. The results show that the ammonia concentration and the pressure of the mixture have significant effects on the system performance of the HRVG.
\end{abstract}

Keywords: entropy; exergy; ammonia-water mixture; heat recovery vapor generator

\section{Introduction}

A thermodynamic analysis based on the First Law can give a good estimation of the expected performance of a thermal system, however, it apparently has the inherent limitations of no distinction between work and heat and no provision for quantifying the quality of heat [1]. The method of entropy and exergy analysis based on the Second Law is well suited for furthering the goal of more effective 
energy resources use, for it enables the location, cause, and true magnitude of waste and losses to be determined [2] and may give a much more meaningful evaluation by indicating the association of irreversibilities of the system $[3,4]$. When heat is transferred in a heat exchanger, a degradation of energy occurs due to irreversibility, but the First Law of Thermodynamics just deals with the quantity of energy and cannot evaluate the quality of energy. However, the Second Law of Thermodynamics deals with quantifying the quality of energy, so it is suitable for evaluating the performance of heat exchanger systems and heat transfer intensification techniques. It shows that not all the energy input into a system can be used effectively and the irreversibility of the heat exchange process could be characterized by the increase of entropy generation [5].

Sciubba [6] presented an extended method of local irreversibilities which can be helpful in assessing the optimal configuration of finned-tube heat exchangers. The method is based on the determination on a local basis of the two components of the entropy generation rate: the one caused by viscous dissipations and the one due to thermal irreversibilities. Naphon [7] performed a Second Law analysis on the heat transfer and flow of a horizontal concentric tube heat exchanger. David et al. [8] introduced an optimization method for improving thermoelectric heat pump performance by operating condition management of the thermoelectric modules and design optimization of the heat exchangers. San [9] carried out a Second Law analysis of heat exchangers for waste heat recovery, while Giangaspero and Sciubba [10] presented an application of the entropy generation minimization method to the pseudo-optimization of the configuration of the heat exchange surfaces in a solar heat exchanger.

An efficient use of low-grade energy sources such as geothermal energy, solar energy, biomass combustion, or waste heat from various industrial processes has become more and more important due to rapidly increasing worldwide energy demands. When the source is low-temperature energy in the form of sensible heat, the thermal performance of a power generation cycle using a pure substance becomes quite poor, because pure fluids have thermal properties of boiling and condensing at a constant temperature under a constant pressure condition, which leads to large temperature differences in the vapor generator and condenser and, in turn, inevitably increases the irreversibilities in the system. However, the use of an ammonia-water mixture, which is a zeotropic binary-mixture, as a working fluid in power generating systems has been found to be a proven technology for efficiently utilizing low-temperature heat sources [11-14].

In the power generation system using ammonia-water mixture instead of pure working fluids, heat can be supplied or rejected at variable temperature but still at constant pressure, since the binary mixture evaporates over a wide range of temperatures. The variable-temperature heat transfer process significantly alleviates the temperature mismatch between hot and cold streams in the heat exchanging components of the system, which then reduces the exergy destruction in the power cycles. The particular use of ammonia in the binary mixture with water possesses several merits other than the fact that ammonia is relatively inexpensive. Ammonia and water have similar molecular weights and, thus, traditional design of steam turbines can be employed in the ammonia-water power cycles with only minor modifications. Also, the boiling point of ammonia is substantially lower than that of water, which makes it practically useful to utilize the low-temperature waste heat in the power generation systems $[15,16]$.

Jonsson and Yan [17] investigated an ammonia-water bottoming cycle and pointed out that higher power output accounted for low boiling temperature of the ammonia-water mixture as well as 
variable-temperature heat transfer. Roy et al. [18] studied an ammonia-water Rankine cycle with finite size thermodynamics and their thermodynamic calculations were carried out in the context of reasonable temperature differences in the heat exchangers. Wagar et al. [19] performed thermodynamic analysis on the ammonia-water based Rankine cycles and suggested that each cycle must be optimized using several parameters due to the nonlinear behavior of the working fluid.

Shi and Che [20] and Wang et al. [21] investigated ammonia-water based power generation cycles using LNG cold energy. Kim et al. [22-24] investigated the thermodynamic performances of ammonia-water based power generation cycles for the recovery of low-temperature heat sources. They showed that the characteristics of temperature distributions in the fluid streams of the heat exchangers vary quite complicatedly and sensitively with changing system parameters. They proposed an efficient and novel method for pinch point assessment in heat exchangers with inside flow of ammonia-water mixture.

In this work, thermodynamic analysis of entropy and exergy is performed for heat recovery vapor generator (HRVG) of ammonia-water mixture to covert low-temperature heat source to useful form of energy. The HRVG consists of pre-heater, evaporator and superheater, and the heat source is in the form of sensible energy. Ammonia mass concentration and pressure of the mixture are considered as the key system parameters of the system, and their effects are investigated on the temperature distributions and the system performance variables such as the effectiveness of heat transfer, entropy generation, and exergy efficiency.

\section{System Analysis}

As previously mentioned, the HRVG consists of pre-heater, evaporator, and superheater, as its schematic diagram is shown in Figure 1. The source fluid enters HRVG with thermal capacity $C_{s}$ and temperature $T_{s}$, where thermal capacity is product of mass flow rate $m_{s}$ and isobaric specific heat $\mathrm{c}_{\mathrm{ps}}$ of source fluid. On the other hand, ammonia-water mixture enters HRVG with mass flow rate $m$, temperature $T_{i n}$, pressure $P$, and ammonia mass concentration $x_{b}$, is heated by the hot source stream, and then leaves HRVG with temperature $T_{\text {out }}$.

Figure 1. Schematic diagram of ammonia-water HRVG.

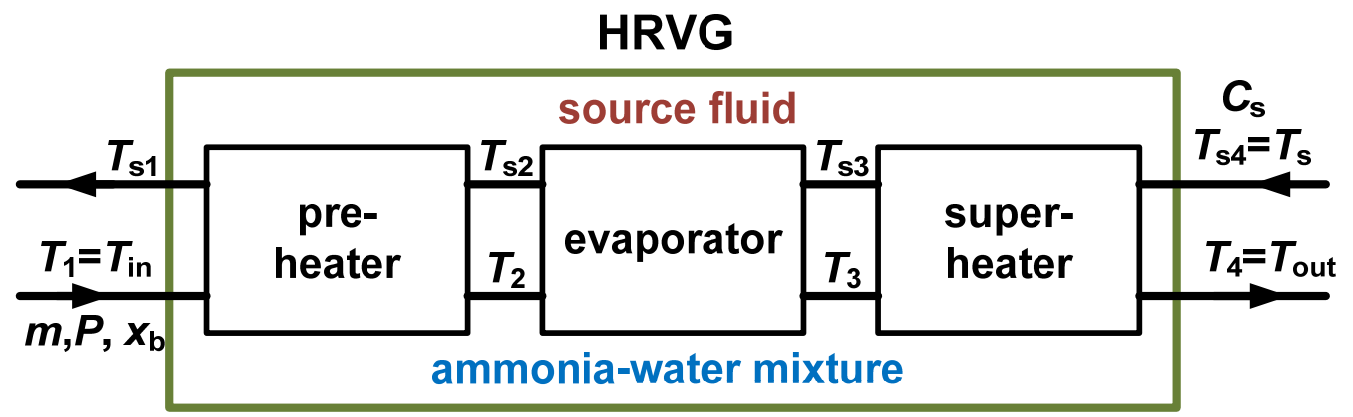

The basic physical equations used to describe the heat transfer process of the heat exchangers are developed with the following simplifying assumptions [5]:

(1) The fluid flow and heat transfer rates are steady. 
(2) Heat loss between the system and environment is negligible so that heat transfer occurs only between hot and cold fluid streams in the heat exchangers.

(3) Pressure drop due to flows inside heat exchangers is negligible so that the pressure inside a heat exchanger is maintained constant.

(4) The kinetic energy and the potential energy changes of the fluids in and out of the heat exchangers are negligible.

(5) The longitudinal heat conduction in the tube walls is negligible.

In this work, thermodynamic properties of liquid and vapor phases of the ammonia-water mixture are evaluated by using the excess Gibbs free energy $G^{E}$ as [25]:

$$
G^{E} / R T=x(1-x)\left[F_{1}+F_{2}(2 x-1)+F_{3}(2 x-1)^{2}\right]
$$

where $R$ is the universal gas constant, $T$ is the absolute temperature, and $x$ is the mole fraction of ammonia in the mixture, and $F_{1}, F_{2}$, and $F_{3}$ are the functions of temperature and pressure. The equilibrium states of liquid and vapor phases are calculated using the methods presented in [22]:

$$
\begin{aligned}
& \mu_{a}^{l}=\left(\frac{\partial G_{m}^{l}}{\partial N_{a}}\right)_{T, P, N_{w}}=\left(\frac{\partial G_{m}^{g}}{\partial N_{a}}\right)_{T, P, N_{w}}=\mu_{a}^{g} \\
& \mu_{w}^{l}=\left(\frac{\partial G_{m}^{l}}{\partial N_{w}}\right)_{T, P, N_{a}}=\left(\frac{\partial G_{m}^{g}}{\partial N_{w}}\right)_{T, P, N_{a}}=\mu_{w}^{g}
\end{aligned}
$$

Here, $\mu$ is the chemical potential, $N_{a}, N_{w}$, and $N$ are numbers of moles of ammonia, water, and the mixture, respectively, while superscripts $l$ and $g$ denote liquid and gas phases, respectively. The Gibbs free energy of $G_{m}$ for liquid or gas phase is denoted as:

$$
G_{m}=N_{a}\left[G_{a}+R T \ln x\right]+N_{w}\left[G_{w}+R T \ln (1-x)\right]+N G^{E}
$$

It is considered in this work that the mass flow rate $m$, ammonia mass concentration $x_{b}$, and inlet and outlet temperatures $T_{\text {in }}\left(=T_{1}\right)$ and $T_{\text {out }}\left(=T_{4}\right)$ of the ammonia-water mixture, and the thermal capacity $C_{s}$ and inlet temperature $T_{s}\left(=T_{s 4}\right)$ of source fluid are specified. Then, the source-fluid temperatures $T_{s 1}, T_{s 2}$ and $T_{s 3}$ can be obtained from the energy balance equations in HRVG:

$$
\begin{aligned}
& Q_{p h}=m\left(h_{2}-h_{1}\right)=C_{s}\left(T_{s 2}-T_{s 1}\right) \\
& Q_{e v}=m\left(h_{3}-h_{2}\right)=C_{s}\left(T_{s 3}-T_{s 2}\right) \\
& Q_{s h}=m\left(h_{4}-h_{3}\right)=C_{s}\left(T_{s 4}-T_{s 3}\right) \\
& Q_{t o t}=m\left(h_{4}-h_{1}\right)=C_{s}\left(T_{s 4}-T_{s 1}\right)
\end{aligned}
$$

where $h$ is the specific enthalpy of the mixture, $Q$ is the heat transfer rate of a heat exchanger, and the subscripts of $p h, e v, s h$, and tot indicate pre-heater, evaporator, superheater, and total system of HRVG, respectively. Note that $h_{2}$ and $h_{3}$ are specific enthalpies at the bubble and dew points of the mixture, respectively, for the prescribed conditions of pressure $P$ and ammonia mass concentration $x_{b}$.

Once the values of the temperature are obtained, the entropy generations, which are equal to the difference of entropy outflow from the system and entropy inflow to the system, can be obtained as follows: 


$$
\begin{aligned}
& \Delta S_{p h}=m\left(s_{2}-s_{1}\right)-C_{s} \ln \left(T_{s 2} / T_{s 1}\right) \\
& \Delta S_{e v}=m\left(s_{3}-s_{2}\right)-C_{s} \ln \left(T_{s 3} / T_{s 2}\right) \\
& \Delta S_{s h}=m\left(s_{4}-s_{3}\right)-C_{s} \ln \left(T_{s 4} / T_{s 3}\right) \\
& \Delta S_{t o t}=m\left(s_{4}-s_{1}\right)-C_{s} \ln \left(T_{s 4} / T_{s 1}\right)
\end{aligned}
$$

where $s$ is the specific entropy of the mixture.

The exergy efficiency (exergy recovery index or second law efficiency) of a heat exchanger $\eta$ may be defined as the ratio of the increased exergy of cold stream to the decreased exergy of hot stream $[2,8]$. Then, the exergy efficiency of each heat exchanger in HRVG can be obtained as follows:

$$
\begin{gathered}
\eta_{p h}=\frac{m}{C_{s}} \frac{\left(h_{2}-h_{1}\right)-T_{0}\left(s_{2}-s_{1}\right)}{\left(T_{s 2}-T_{s 1}\right)-T_{0} \ln \left(T_{s 2} / T_{s 1}\right)} \\
\eta_{e v}=\frac{m}{C_{s}} \frac{\left(h_{3}-h_{2}\right)-T_{0}\left(s_{3}-s_{2}\right)}{\left(T_{s 3}-T_{s 2}\right)-T_{0} \ln \left(T_{s 3} / T_{s 2}\right)} \\
\eta_{s h}=\frac{m}{C_{s}} \frac{\left(h_{4}-h_{3}\right)-T_{0}\left(s_{4}-s_{3}\right)}{\left(T_{s 4}-T_{s 3}\right)-T_{0} \ln \left(T_{s 4} / T_{s 3}\right)} \\
\eta_{t o t}=\frac{m}{C_{s}} \frac{\left(h_{4}-h_{1}\right)-T_{0}\left(s_{4}-s_{1}\right)}{\left(T_{s 4}-T_{s 1}\right)-T_{0} \ln \left(T_{s 4} / T_{s 1}\right)}=\frac{\Delta E_{w}}{\Delta E_{s}}=1-\frac{T_{0} \Delta S_{t o t}}{\Delta E_{s}}
\end{gathered}
$$

where the subscript 0 indicates the dead state.

\section{Results and Discussion}

In the present study, thermodynamic analysis of the HRVG of ammonia-water mixture is carried out. The basic data of the system variables are as follows: $T_{s}=200{ }^{\circ} \mathrm{C}, T_{\text {in }}=30{ }^{\circ} \mathrm{C}, T_{\text {out }}=190{ }^{\circ} \mathrm{C}$, $T_{0}=298.15 \mathrm{~K}, C_{s}=10 \mathrm{~kW} / \mathrm{K}, P=20 \mathrm{bar}$, and $m=0.3 \mathrm{~kg} / \mathrm{s}$. The key parameters in this study are the ammonia mass concentration and pressure in the stream of ammonia-water mixture. Note that, when one parameter is varied in the parametric analysis, others are kept constant as the basic data.

\subsection{Temperature Distributions}

In contrast to the pure substance in which phase transition occurs at a constant saturation temperature for a specified pressure, the phase transition of the zeotropic mixture as a working fluid occurs over a wide range of temperature for a specified pressure. The phase transition starts at the bubble point and ends at the dew point of the mixture. Some typical temperature distributions of the hot and cold streams in HRVG are illustrated in Figure 2 for various: (a) ammonia concentrations (at $P=20$ bar) and (b) pressures (with $x_{\mathrm{b}}=60 \%$ ) of the ammonia-water mixture with respect to relative heat transfer which is defined as the ratio of heat transfer to total heat transfer in HRVG. Note that the inlet and outlet temperatures of working fluid are given as fixed values of 30 and $190{ }^{\circ} \mathrm{C}$ in order to show the effects of ammonia concentration and pressure on the variable temperature phase transition. 
Figure 2. Temperature distributions in HRVG for various (a) ammonia concentrations and (b) pressures of ammonia-water mixture.

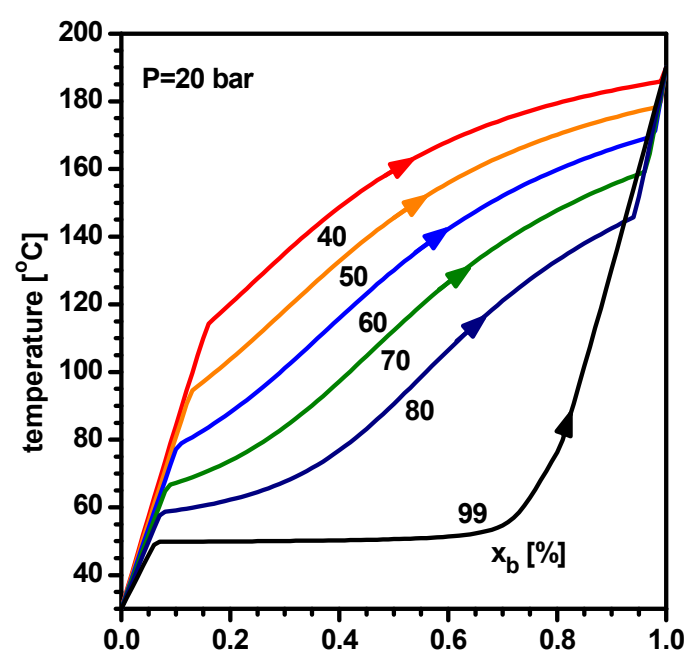

(a) relative heat transfer

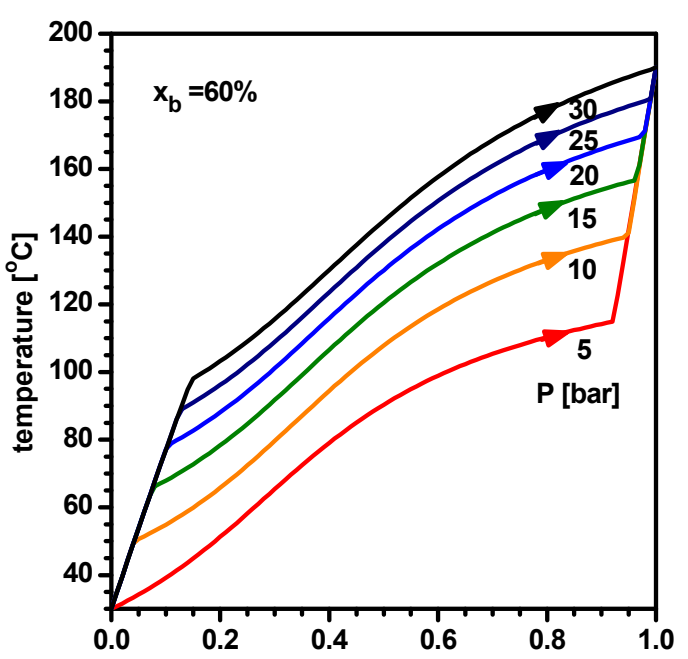

(b) relative heat transfer

When the ammonia concentration is $99 \%$, the phase transition is naturally similar to that of pure ammonia by showing that most of phase change occurs at constant temperature. As the ammonia concentration decreases for a fixed pressure or as the pressure increases for a fixed ammonia concentration, both the bubble and dew temperatures as well as the temperature range of phase transition rise and the portion of subcooled liquid increases, while the portion of superheated vapor decreases. It is usually shown that the pinch point of a heat exchanger with phase change occurs at the bubble point, if the working fluid is made of a single substance. However, in the heat exchangers using a zeotropic mixture as a working fluid such as ammonia-water mixture, the pinch point may occur at a middle point instead of the bubble point due to the nonlinear behavior of the phase transition process, thus, cautions may be required in the pinch point calculations [22,23].

Figure 3 a shows the saturation temperatures (bubble and dew points) of ammonia-water mixture for the varying ammonia concentration and pressure. For example, the mixture of $x_{b}=58.7 \%$ is a saturated liquid at $30{ }^{\circ} \mathrm{C}$ and 5 bar (point i5) and, as the ammonia concentration increases, it becomes the state of saturated liquid-vapor mixture. Similarly, the mixture of $x_{b}=61.2 \%$ is a saturated vapor at $190{ }^{\circ} \mathrm{C}$ and 30 bar (point e30) and, as the ammonia concentration increases, it becomes a superheated vapor. In Figure $3 b$, the vaporization heat of ammonia-water mixture is shown to decrease with increasing pressure or ammonia concentration.

With given enthalpy $h$ of ammonia-water mixture, let us define the enthalpy ratio as:

$$
y=\frac{h-h_{f}}{h_{g}-h_{f}}
$$

where $h_{f}$ and $h_{g}$ are the enthalpy of saturated liquid and saturated vapor, respectively, at given pressure and ammonia concentration. Thus, the ammonia-water mixture is expected to be a subcooled liquid with $y<0$, a saturated liquid-vapor mixture with $0<y<1$, and a superheated vapor with $y>1$. 
Figure 3. The effects of ammonia concentration and pressure on (a) saturation temperatures and (b) vaporization heat for ammonia-water mixture.

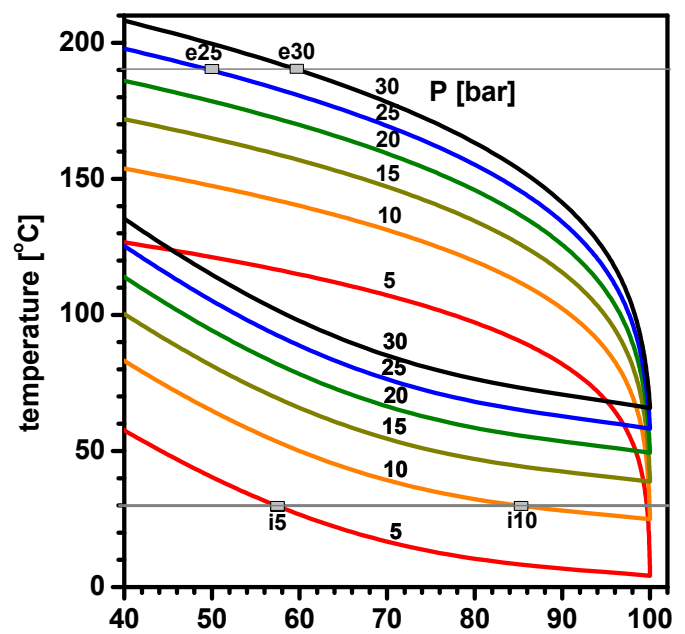

(a) ammonia concentration [\%]

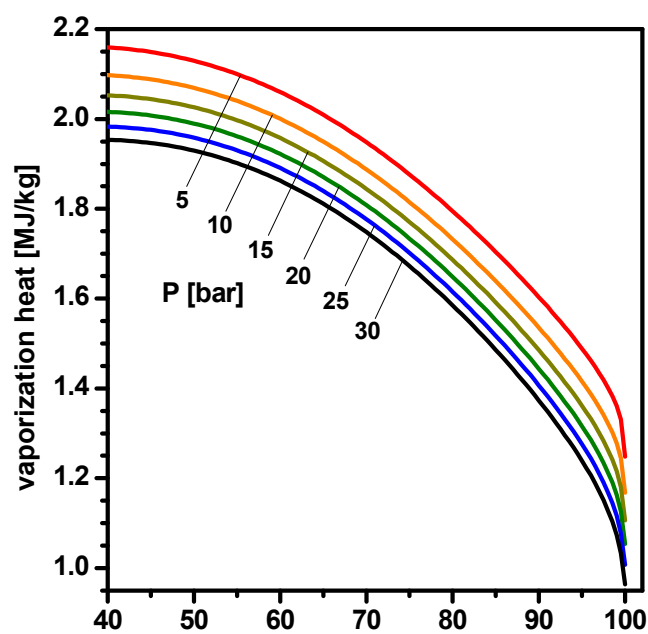

(b) ammonia concentration [\%]

Figure 4 shows the change of enthalpy ratio at 30 and $190{ }^{\circ} \mathrm{C}$ with respect to ammonia concentration and pressure. If the temperature is low enough, such as $30^{\circ} \mathrm{C}$ in Figure $4 \mathrm{a}$, the mixture stays as a subcooled liquid at higher pressure. However, at low pressures of 5 or 10 bar, the enthalpy ratio exhibits a large increase after the state of saturated liquid (point i5 or i10) with further increase of ammonia concentration. If the temperature is as high as $190{ }^{\circ} \mathrm{C}$ in Figure $4 \mathrm{~b}$, the trends are quite opposite to the ones shown in Figure 4a. In the case where the working fluid exiting the heat exchanger goes into turbine, the limitation of ammonia concentration can be determined (point e25 or e30) to maintain the working fluid as a superheated vapor.

Figure 4. Change of enthalpy ratio of ammonia-water mixture at (a) $30{ }^{\circ} \mathrm{C}$ and (b) $190{ }^{\circ} \mathrm{C}$ with respect to ammonia concentration and pressure.

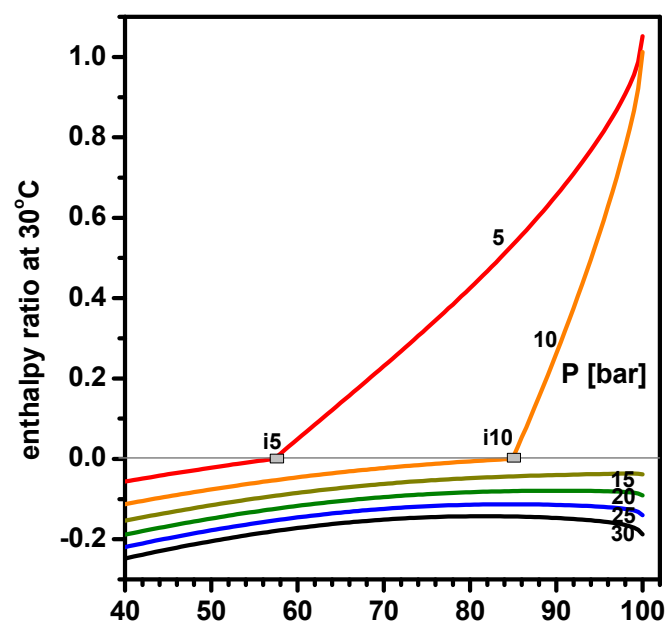

(a) ammonia concentration [\%]

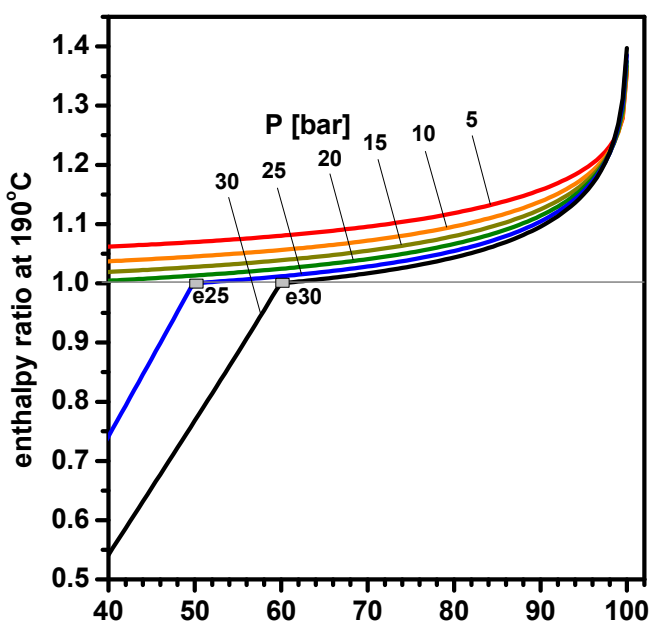

(b) ammonia concentration [\%]

\subsection{Heat Transfer}

Figure 5 shows the heat transfers in pre-heater, evaporator, and superheater with the changes of ammonia concentration and pressure of working fluid. Heat transfer in pre-heater increases with 
decreasing ammonia concentration or increasing pressure, due to the elevated temperature of the bubble point of the mixture for a specified inlet temperature of the mixture. When the pressure is low and the ammonia concentration is high (for example, $P=5$ bar and $x_{b}=60 \%$ ), the heat transfer reduces to zero, which indicates that the incoming working fluid is a saturated mixture of liquid and vapor. Heat transfer in the superheater drops with decreasing ammonia concentration or increasing pressure because of the elevated temperature of the dew point in the mixture for a specified outlet temperature of the mixture. When the pressure is high and the ammonia concentration is low (for example, $P=30$ bar and $x_{b}=50 \%$ ), the heat transfer becomes zero and, at this time, it is because the working fluid leaving the evaporator reaches the specified outlet temperature.

Figure 5. Heat transfers in pre-heater, evaporator, and superheater for various ammonia concentration and pressure of working fluid.

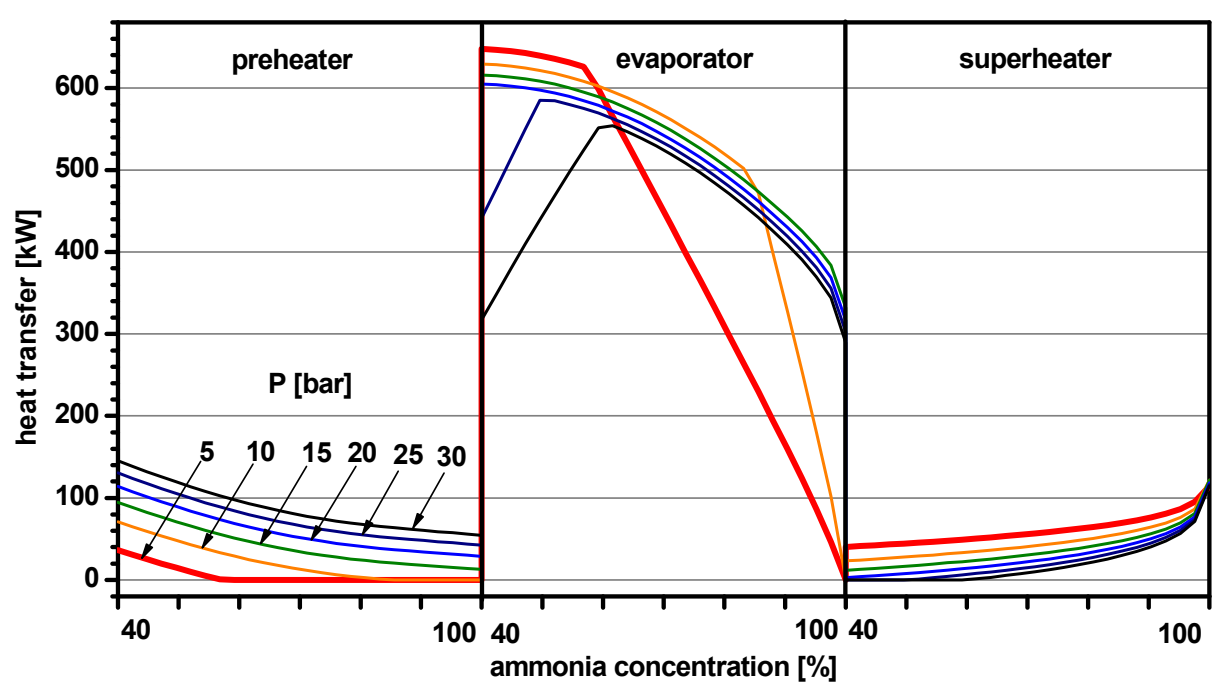

In general, heat transfer in the evaporator is greater than that in the pre-heater or superheater and decreases with increasing ammonia concentration or pressure of the working fluid because of the reduced vaporization heat of the working fluid. The middle range of pressure (15 or 20 bar) in Figure 4 belongs to this monotonic decrease of heat transfer with ammonia concentration in evaporator, as the working fluid is subcooled liquid or superheated vapor at the inlet or exit, respectively, for all degree of ammonia concentration in the figures. When the ammonia concentration is high and pressure is low, however, the decreasing rate of heat transfer with respect to the ammonia concentration becomes higher, since the incoming working fluid is the saturated mixture of liquid and vapor instead of usual subcooled liquid, which can be verified in the case of 5 or 10 bar in Figure $4 \mathrm{a}$. When the ammonia concentration is low and pressure is high, the heat transfer firstly increases with ammonia concentration before its decline at the range of higher ammonia concentration. This is because the working fluid leaving evaporator is now saturated mixture of liquid and vapor, as this is depicted in the cases of 25 or 30 bar in Figure 4b.

The effectiveness of heat exchanger $\varepsilon$ is defined as the ratio between actual heat transfer rate and the maximum possible heat transfer rate and it can be approximately obtained as follows:

$$
\varepsilon=\frac{T_{s}-T_{s 1}}{T_{s}-T_{i n}}
$$


Figure 6 illustrates the effects of ammonia concentration and pressure of working fluid on the effectiveness of heat exchanger. Since the heat transfer in evaporator is dominant in total value, the effectiveness exhibits quite similar changes shown in evaporator of Figure 5. As long as the ammonia-water mixture is a subcooled liquid at the inlet temperature of $30{ }^{\circ} \mathrm{C}$ and a superheated vapor at $190{ }^{\circ} \mathrm{C}$, the effectiveness of $\mathrm{HRVG}$ at different pressures falls onto one declining line with increasing ammonia concentration. However, if either the inlet or exit condition of working fluid is in a saturated state, which is determined by pressure and ammonia concentration, it could result in a significant decrease of effectiveness.

Figure 6. Heat exchanger effectiveness of HRVG for various ammonia concentrations and pressures of working fluid.

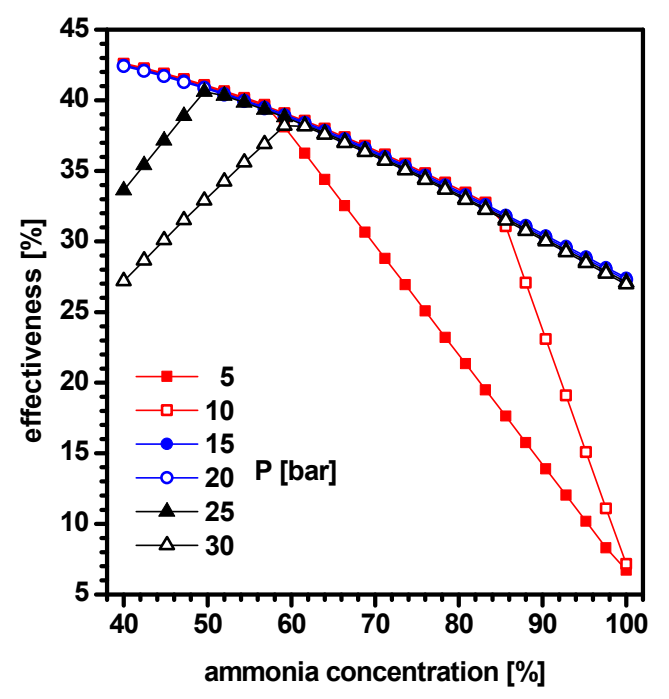

\subsection{Entropy Generation}

As aforementioned, the entropy generation is a measure of irreversibility and can be obtained from Equations (9)-(12) for pre-heater, evaporator, superheater, and HRVG, respectively. Figure 7 shows the entropy generation in pre-heater, evaporator, and superheater, respectively, as functions of the ammonia concentration and pressure of working fluid. The entropy generation in the pre-heater shows an increasing tendency when the ammonia concentration decreases or the pressure of working fluid increases, which is similar to the case of the heat transfer in the pre-heater. In contrast, the entropy generation in the superheater increases with increasing ammonia concentration or decreasing pressure of working fluid, which is similar to the case of the heat transfer in the superheater.

However, it can be seen from the figure that entropy generation in the evaporator is generally greater than that in the pre-heater or superheater, and has a peak value with respect to the ammonia concentration of the working fluid. The ammonia concentration corresponding to the peak value for entropy generation increases with the pressure of working fluid. As the ammonia concentration increases, temperature mismatch between hot and cold streams in the heat exchanger usually becomes worse and yields the increase of entropy generation or irreversibility. However, at low pressure (5 or 10 bar), with the increase of ammonia concentration, the working fluid at the inlet goes into to the saturated state. Thus, this starts the alleviation of temperature mismatch and creates the peak value for 
entropy generation at the ammonia concentration that indicates the saturated liquid state, which is labeled as point i5 or i10 in Figures 3a and 4a. Note that the small peaks for high pressure cases near the $100 \%$ ammonia concentration are due to the steep increase of enthalpy ratio shown in Figure $4 \mathrm{~b}$.

Figure 7. Entropy generation in pre-heater, evaporator, and superheater for various ammonia concentrations and pressures of working fluid.

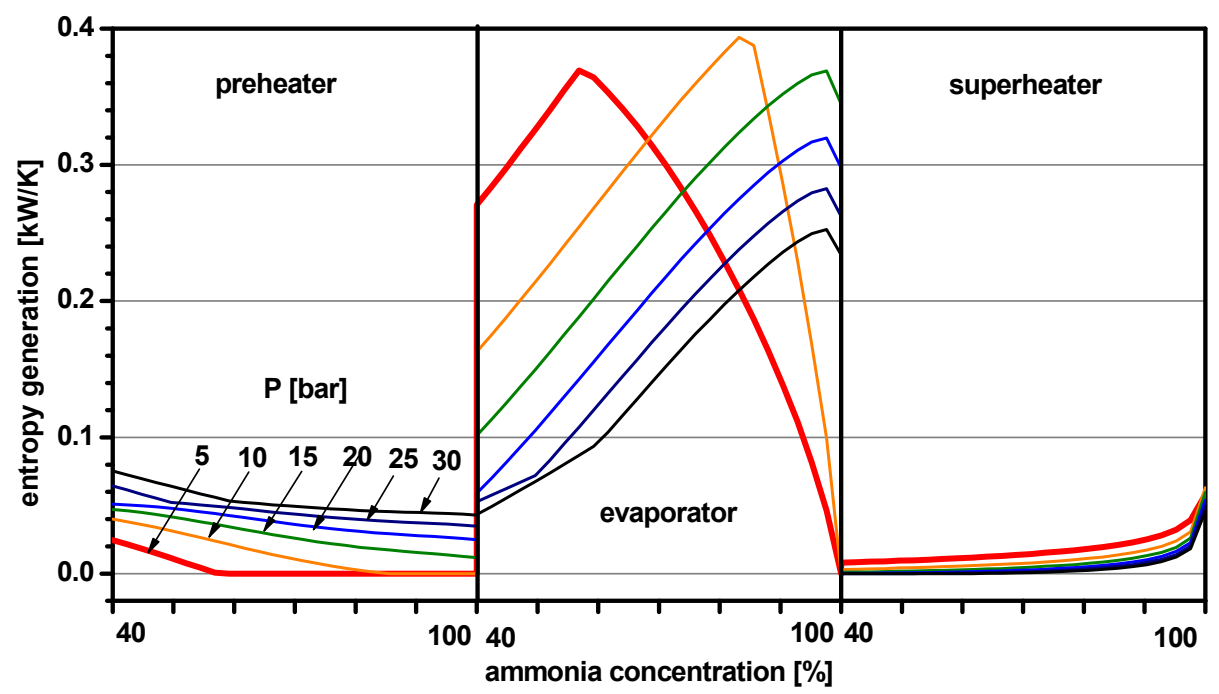

Figure 8. Entropy generation of HRVG with changes of ammonia concentration for different pressures of working fluid.

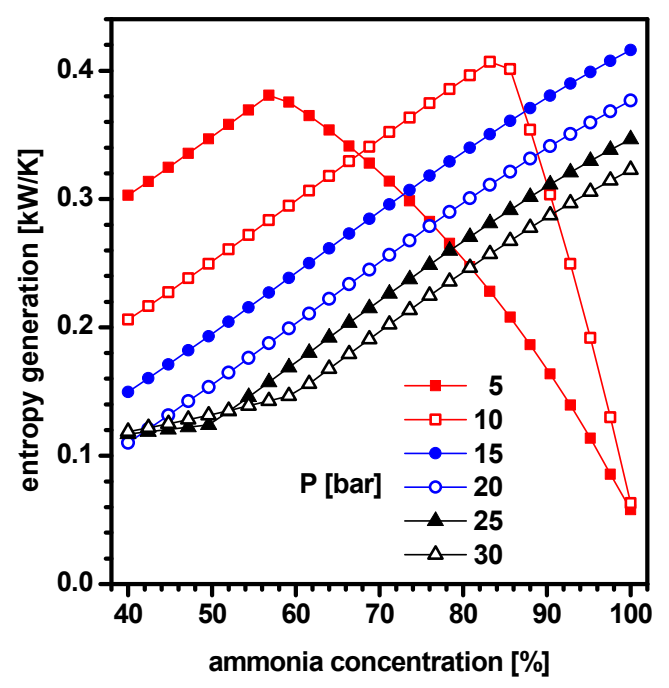

Figure 8 illustrates the effects of ammonia concentration and pressure of working fluid on the entropy generation of total system. When the pressure is high $(P=15,20,25,30$ bar $)$, the entropy generation shows a monotonous increasing tendency with increasing ammonia concentration or decreasing pressure of working fluid. When the pressure is low enough ( $P=5,10$ bar), however, the entropy generation first increases with the ammonia concentration, reaches a peak value, and then decreases to a very small value. Therefore, when the ammonia concentration has a high value near $100 \%$, the entropy generation as well as the effectiveness of the system becomes very small. As discussed earlier, this behavior at lower pressure is due to the fact that the working fluid becomes a 
saturated liquid-vapor mixture, not a subcooled liquid any more, at the inlet, when the ammonia concentration increases past a certain value. Therefore, at low pressures, with increasing ammonia concentration, the entropy generation of the system increases first (subcooled liquid at the inlet), and then starts to decrease (saturated liquid-vapor mixture at the inlet). Also, the working fluid becomes simply saturated vapor, as the ammonia concentration approaches $100 \%$ or the working fluid is quite a pure substance. Hence, the function of evaporator is meaningless and it is reflected on the very small value of heat transfer or entropy generation in this case.

\subsection{Exergy Efficiency}

As the HRVG is employed in a low-grade heat recovery process, thermal exergy is transferred from a hot stream to a cold stream. The exergy efficiency of a heat exchanger can be viewed as the net recovered thermal exergy in the cold stream normalized by the available thermal exergy in the hot stream as listed in Equations (13)-(16). Figure 9 shows the exergy efficiencies of pre-heater, evaporator, and superheater for various ammonia concentrations and pressures of working fluid.

Figure 9. Exergy efficiency as a function of ammonia concentration for pre-heater, evaporator, and superheater.

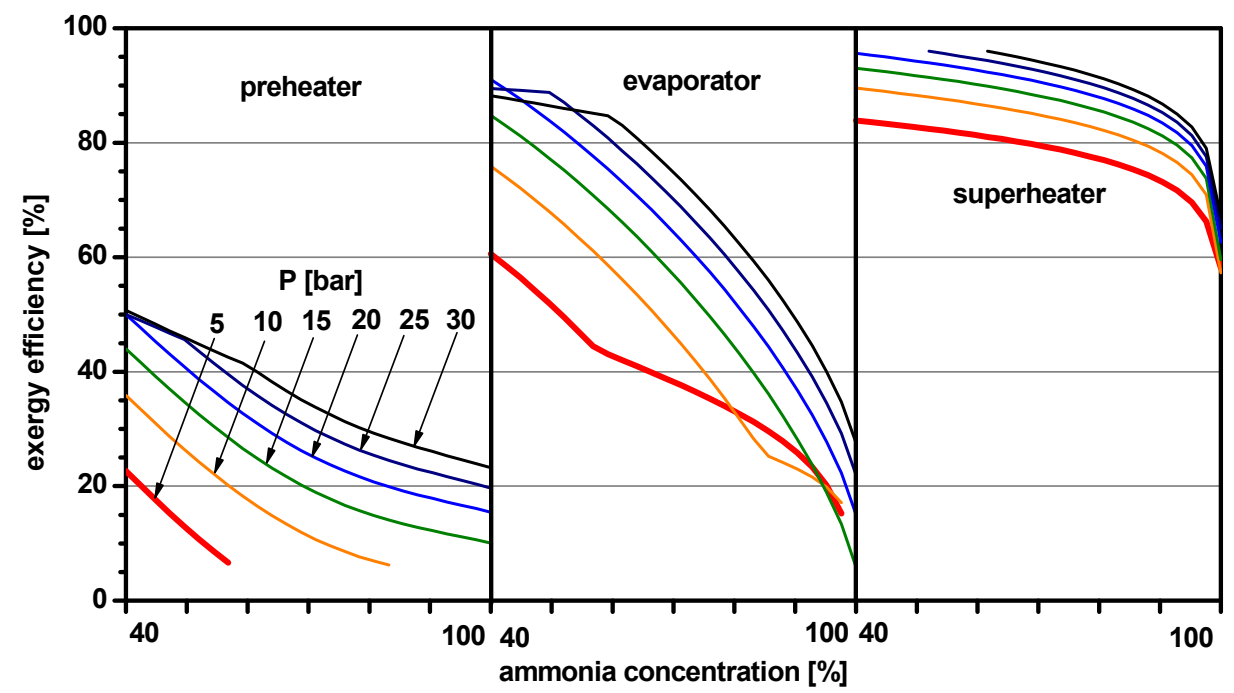

As is seen in the figure, the exergy efficiency of each heat exchanger shows the decreasing tendency with increasing ammonia concentration. Especially, it is reduced to a very small value as ammonia concentration approaches $100 \%$. As the pressure of working fluid increases for a specified ammonia concentration, the exergy efficiency generally increases except for low pressure and high concentration or high pressure and low concentration. This can be explained as follows. In hot stream (source fluid), the change of exergy is insensitive to pressure change. In contrast, the exergy in cold stream (working fluid) can increase sensitively with the increase of pressure or decrease of ammonia concentration, resulting in those behaviors of exergy efficiency in Figure 9. The inconsistency to this trend that appears in the figure is due to the aforementioned effects of inlet or exit conditions of working fluid being or crossing over the bubble or dew points for the cases being either low pressure and high ammonia concentration or high pressure and low ammonia concentration. 
Figure 10 shows the exergy efficiency of HRVG for various ammonia concentrations and pressures of working fluid. It can be seen from the figure that the exergy efficiency of each heat exchanger generally decreases with increasing ammonia concentration or decreasing pressure of working fluid. First, it has a local maximum value with respect to ammonia concentration for low ammonia concentration and high pressure of working fluid due to the fact that the exit condition of working fluid experiences dew point and is still at saturated state.

Figure 10. Exergy efficiency of HRVG for various ammonia concentrations and pressures of working fluid.

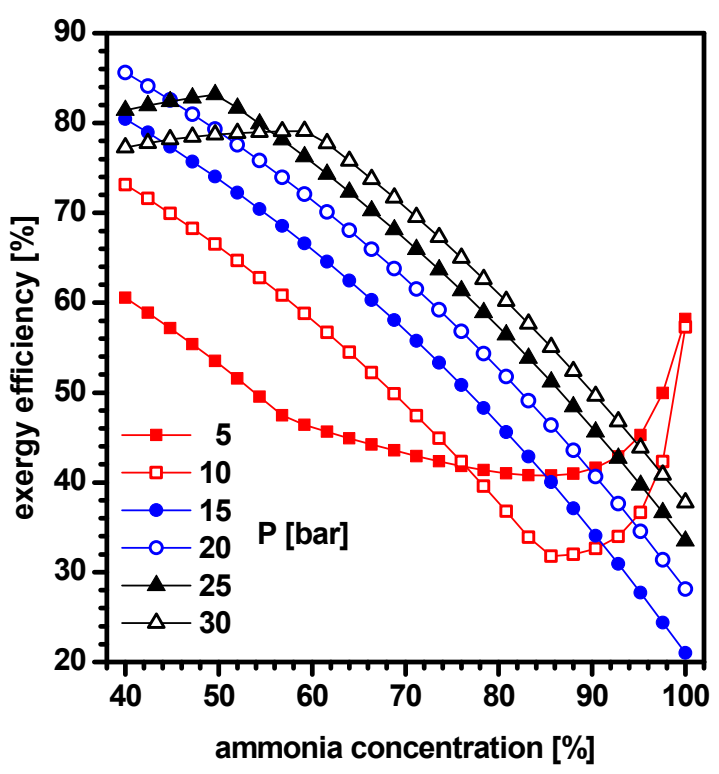

In contrast, it has a local minimum value with respect to ammonia concentration for high ammonia concentration and low pressure of working fluid. This is related to the substantial decrease of entropy generation with higher ammonia concentration in evaporator by having the working fluid as saturated liquid-vapor mixture at the inlet, combined with the change of exergy in pre-heater and superheater. Furthermore, it can be observed from Figures 8 and 10 that the extremes (maximum for entropy generation on Figure 8 and minimums for exergy efficiency on Figure 10) are not at the same ammonia concentrations for 5 bar (at $57.3 \%$ and $84.9 \%$ ) but are quite close for 10 bar (at $84.9 \%$ and $84.9 \%$ ), respectively. It can be explained as follows: considering the rightmost part of Equation (16) and introducing two supplementary functions for the total entropy generation $\left(\Delta S_{t o t}\right)$ and the exergy decrease in source fluid $\left(\Delta E_{s}\right)$ such as:

$$
\begin{gathered}
F\left(x_{b}\right)=\frac{d\left(\Delta S_{t o t}\right) / d x_{b}}{\Delta S_{t o t}}=\frac{d \ln \left(\Delta S_{t o t}\right)}{d x_{b}} \\
G\left(x_{b}\right)=\frac{d\left(\Delta E_{s}\right) / d x_{b}}{\Delta E_{s}}=\frac{d \ln \left(\Delta E_{s}\right)}{d x_{b}}
\end{gathered}
$$

it is readily found that the total entropy generation and the total exergy efficiency have extremes with respect to ammonia concentration at the zeroes of $F$ and at the intersection between $F$ and $G$, respectively. These extreme points are pictorially given in Figure 11 for the pressure between 2.5 and 15 bar with an interval of 2.5 bar. It is to be noted that the ammonia concentrations giving maximum 
entropy generation for 5 and 10 bar coincide with those of the points marked as i5 and i10, respectively, in Figure 4. The ammonia concentration giving maximum entropy generation increases with the pressure and eventually reaches $100 \%$ when the pressure becomes high enough (such as 15 bar or above). The total exergy efficiency shows a qualitatively similar but quantitatively different dependence on ammonia concentration; concentrations at minimum efficiencies are higher than those of maximum entropy generations and comparatively insensitive to the change of pressure.

Figure 11. Functions $F$ and $G$ for various ammonia concentrations and pressures of working fluid.

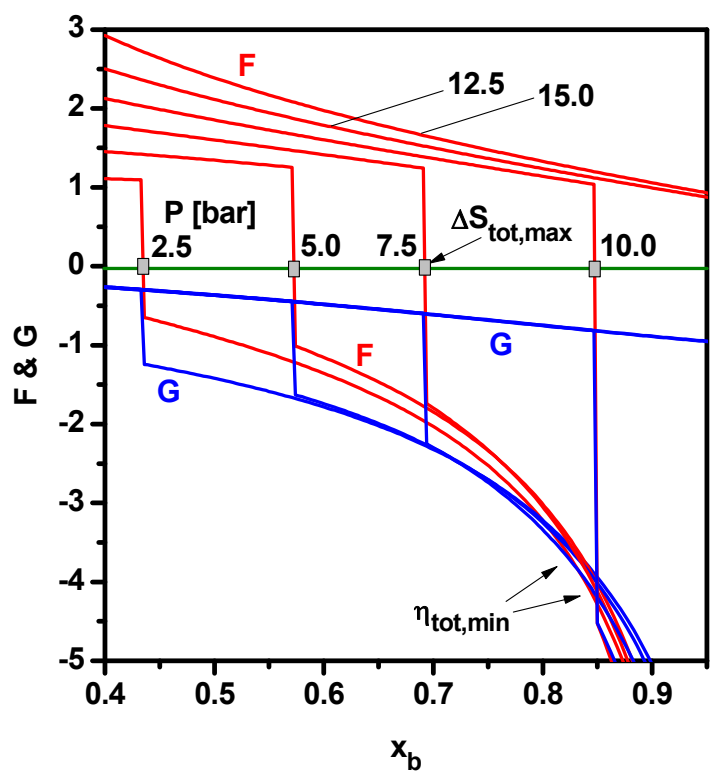

\section{Conclusions}

In this study, a performance analysis based on the First and Second Laws of thermodynamics is carried out for the heat recovery vapor generator (HRVG) of an ammonia-water mixture. The heat source is a low-temperature heat source in the form of sensible energy and the HRVG consists of pre-heater, evaporator, and superheater. The ammonia mass concentration and pressure of the mixture are considered as the key parameters, while other system parameters are prescribed. The results of the present analysis show that the temperature distribution changes depend dramatically on the ammonia concentration and pressure, which reveals that the nonlinear behaviors of temperature distribution in zeotropic mixture should be considered carefully for thermodynamic performance analyses. Simulation results show that the ammonia concentration and the pressure of the mixture exhibit significant effects on the system performance such as the effectiveness of heat exchanger, entropy generation and exergy efficiency for pre-heater, evaporator, superheater, and total HRVG system. In general, the entropy generation increases but the exergy efficiency decreases with increasing ammonia concentration or decreasing pressure of the mixture. However, the exergy efficiency possess a local minimum value with respect to ammonia concentration for high ammonia concentration and low pressure of working fluid, and has a local maximum value with respect to ammonia concentration for low ammonia concentration and high pressure of working fluid. 


\section{Acknowledgments}

This research was supported by Basic Science Research Program through the National Research Foundation of Korea (NRF) funded by the Ministry of Education, Science and Technology (No. 2012-013929).

\section{Author Contributions}

K. H. Kim designed the research with H. J. Ko, and carried out the theoretical analysis as well as establishing system modeling. K. H. Kim, H. J. Ko and K. Kim analyzed the results and wrote the article. All authors read and approved the final manuscript.

\section{Conflicts of Interest}

The authors declare no conflict of interest.

\section{References}

1. Khaliq, A. Exergy analysis of gas turbine trigeneration system for combined production of power and heat and refrigeration. Int. J. Refrig. 2009, 32, 534-545.

2. Bejan, A. Advanced Engineering Thermodynamics, 3rd ed.; Wiley: New York, NY, USA, 2006.

3. Bejan, A.; Tsatsaronis, G.; Moran, M. Thermal Design and Optimization; Wiley: New York, NY, USA, 1996.

4. Lior, N.; Zhang, N. Energy, exergy, and second law performance criteria. Energy 2007, 32, 281-296.

5. Tarlet, D.; Fan, Y.; Roux, S.; Luo, L. Entropy generation analysis of a mini heat exchanger for heat transfer intensification. Exp. Therm. Fluid Sci. 2014, 53, 119-126.

6. Sciubba, E. A minimum entropy generation procedure for the discrete pseudo-optimization of finned-tube heat exchangers. Rev. Gen. Therm. 1996, 35, 517-525.

7. Naphon, P. Second law analysis on the heat transfer of the horizontal concentric tube heat exchanger. Int. Commun. Heat Mass 2006, 33, 1029-1041.

8. San, J.Y. Second-law performance of heat exchangers for waste heat recovery. Energy 2010, 35, 1936-1945.

9. David, B.; Ramousse, J.; Luo, L. Optimization of thermoelectric heat pumps by operating condition management and heat exchanger design. Energy Convers. Manag. 2012, 60, 125-133.

10. Giangaspero, G.; Sciubba, E. Application of the entropy generation minimization method to a solar heat exchanger: A pseudo-optimization design process based on the analysis of the local entropy generation maps. Energy 2013, 58, 52-65.

11. Ibrahim, O.M. Design consideration for ammonia-water Rankine cycle. Energy 1996, 21, 835-841.

12. Prisyazhniuk, V.A. Alternative trends in development of thermal power plant. Appl. Therm. Eng. 2008, 28, 190-194.

13. Kiani, N.; Akisawa, A.; Kashiwagi, T. Thermodynamic analysis of loadleveling hyper energy converting and utilization system. Energy 2008, 33, 400-409. 
14. Nowak, W.; Stachel, A.A.; Borsukiewicz-Gozdur, A. Possibilities of implementation of a absorption heat pump in realization of the Clausius-Rankine cycle in geothermal power station. Appl. Therm. Eng. 2008, 28, 335-340.

15. Lolos, P.A.; Rogdakis, E.D. A Kalina power cycle driven by renewable energy sources. Energy 2009, 34, 457-464.

16. Ogriseck, S. Integration of Kalina cycle in a combined heat and power plant, a case study. Appl. Therm. Eng. 2009, 29, 2843-2848.

17. Jonsson, M.; Yan, J. Ammonia-water bottoming cycles: A comparison between gas engines and gas diesel engines as prime movers. Energy 2001, 26, 31-44.

18. Roy, P.; Désilets, M.; Galanis, N.; Nesreddine, H.; Cayer, E. Thermodynamic analysis of a power cycle using a low-temperature source and a binary $\mathrm{NH}_{3}-\mathrm{H}_{2} \mathrm{O}$ mixture as working fluid. Int. J. Therm. Sci. 2010, 49, 48-58.

19. Wagar, W.R.; Zamfirescu, C.; Dincer, I. Thermodynamic performance assessment of an ammonia-water Rankine cycle for power and heat production. Energy Convers. Manag. 2010, 51, 2501-2509.

20. Shi, X.; Che, D. A combined power cycle utilizing low-temperature waste heat and LNG cold energy. Energy 2009, 50, 567-575.

21. Wang, J.; Yan, Z.; Wang, M. Thermodynamic analysis and optimization of an ammonia-water power system with LNG (liquefied natural gas) as its heat sink. Energy 2013, 50, 513-522.

22. Kim, K.H.; Han, C.H.; Kim, K. Effects of ammonia concentration on the thermodynamic performances of ammonia-water based power cycles. Thermochim. Acta 2012, 530, 7-16.

23. Kim, K.H.; Ko, H.J.; Kim, K. Assessment of pinch point characteristics in heat exchangers and condensers of ammonia-water based power cycles. Appl. Energy 2014, 113, 970-981.

24. Kim, K.H.; Han, C.H.; Kim, K. Comparative exergy analysis of ammonia-water based Rankine cycles with and without regeneration. Int. J. Exergy 2013, 12, 344-361.

25. Xu, F.; Goswami, D.Y. Thermodynamic properties of ammonia-water mixtures for power-cycle application. Energy 1999, 24, 525-536.

(C) 2014 by the authors; licensee MDPI, Basel, Switzerland. This article is an open access article distributed under the terms and conditions of the Creative Commons Attribution license (http://creativecommons.org/licenses/by/3.0/). 